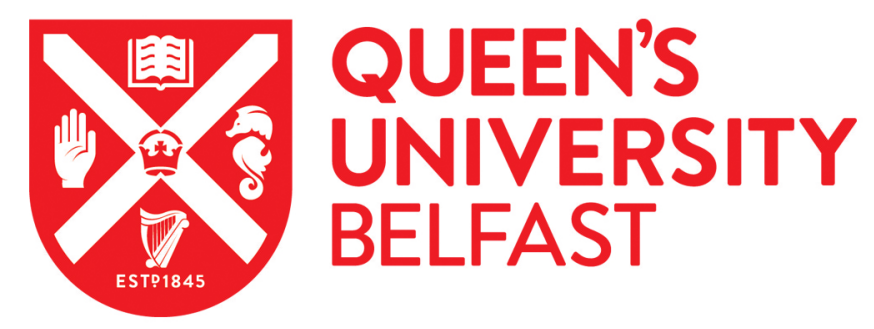

\title{
A pilot study of a low-tilt biphasic waveform for transvenous cardioversion of atrial fibrillation: improved efficacy compared with conventional capacitor-based waveforms in patients
}

Glover, B. M., McCann, C. J., Manoharan, G., Walsh, S. J., Moore, M. J., Allen, J. D., Escalona, O., Mc, A. J., Trouton, T. G., Stevenson, M., Roberts, M. J., \& Adgey, A. J. (2008). A pilot study of a low-tilt biphasic waveform for transvenous cardioversion of atrial fibrillation: improved efficacy compared with conventional capacitor-based waveforms in patients. PACE, 31(8), 1020-1024.

Published in:

PACE

Queen's University Belfast - Research Portal:

Link to publication record in Queen's University Belfast Research Portal

\section{General rights}

Copyright for the publications made accessible via the Queen's University Belfast Research Portal is retained by the author(s) and / or other copyright owners and it is a condition of accessing these publications that users recognise and abide by the legal requirements associated with these rights.

Take down policy

The Research Portal is Queen's institutional repository that provides access to Queen's research output. Every effort has been made to ensure that content in the Research Portal does not infringe any person's rights, or applicable UK laws. If you discover content in the

Research Portal that you believe breaches copyright or violates any law, please contact openaccess@qub.ac.uk. 


\section{A Pilot Study of a Low-Tilt Biphasic Waveform for Transvenous Cardioversion of Atrial Fibrillation: Improved Efficacy Compared with Conventional Capacitor-Based Waveforms in Patients}

BENEDICT M. GLOVER, M.D., * CONOR J. McCANN, M.D., * GANESH MANOHARAN, M.D., * SIMON J. WALSH, M.D., * MICHAEL J. MOORE, M.D., * JAMES D. ALLEN, M.D.,† OMAR ESCALONA, PH.D.,‡ JOHN MCC. ANDERSON, D.PHIL. „ TOM G. TROUTON, M.D., $\S$ MIKE STEVENSON, B.Sc., MICHAEL J. ROBERTS, M.D., * and JENNIFER AA. ADGEY, M.D.* From the * Regional Medical Cardiology Center, Royal Victoria Hospital, Belfast, Northern Ireland; +Department of Physiology, Queens University of Belfast, Belfast, Northern Ireland; ‡Department of Engineering, University of Ulster, Jordanstown, Northern Ireland; $§$ Department of Cardiology, Antrim Area Hospital, Antrim, Northern Ireland; and $\uparrow$ Clinical Research Support Centre, Education Centre, Royal Victoria Hospital, Belfast, Northern Ireland

Background: The optimal waveform tilt for defibrillation is not known. Most modern defibrillators used for the cardioversion of atrial fibrillation (AF) employ high-tilt, capacitor-based biphasic waveforms.

Methods: We have developed a low-tilt biphasic waveform for defibrillation. This low-tilt waveform was compared with a conventional waveform of equivalent duration and voltage in patients with AF. Patients with persistent $A F$ or AF induced during a routine electrophysiology study (EPS) were randomized to receive either the low-tilt waveform or a conventional waveform. Defibrillation electrodes were positioned in the right atrial appendage and distal coronary sinus. Phase 1 peak voltage was increased in a stepwise progression from $50 \mathrm{~V}$ to $300 \mathrm{~V}$. Shock success was defined as return of sinus rhythm for $\geq 30$ seconds.

Results: The low-tilt waveform produced successful termination of persistent AF at a mean voltage of $223 \mathrm{~V}(8.2 \mathrm{~J})$ versus $270 \mathrm{~V}(6.7 \mathrm{~J})$ with the conventional waveform $(P=0.002$ for voltage, $P=n s$ for energy). In patients with induced AF the mean voltage for the low-tilt waveform was $91 \mathrm{~V}$ (1.6 J) and for the conventional waveform was $158 \mathrm{~V}(2.0 \mathrm{~J})(P=0.005$ for voltage, $P=n s$ for energy). The waveform was much more successful at very low voltages (less than or equal to $100 \mathrm{~V}$ ) compared with the conventional waveform (Novel: $82 \%$ vs Conventional 22\%, $P=0.008$ ).

Conclusion: The low-tilt biphasic waveform was more successful for the internal cardioversion of both persistent and induced AF in patients (in terms of leading edge voltage). (PACE 2008; 31:1020-1024)

atrial fibrillation, direct current cardioversion

\section{Introduction and Background}

Restoration of sinus rhythm is an important strategy for patients with symptomatic atrial fibrillation (AF). Internal cardioversion can be used at low voltages for patients in whom AF is stimulated during an electrophysiology study (EPS), which does not spontaneously revert, ${ }^{1}$ during AF ablation $^{2}$ or in cases of failed transthoracic direct current cardioversion. The ideal principle in all these cases is to develop a waveform, which is highly successful at a low voltage, thus limiting the number of shocks required. Various waveform

Funding Source: Northern Ireland Chest, Heart and Stroke Association.

Conflicts of Interest: None.

Address for reprints: Benedict M. Glover, M.D., Regional Medical Cardiology Center, Royal Victoria Hospital, Grosvenor Road, Belfast, Northern Ireland, UK, BT12 6BA. Fax: +442890312907; e-mail: ben.glover@hotmail.com

Received January 29, 2008; revised March 13, 2008; accepted May 4, 2008. parameters have been studied in order to increase success. We have previously shown that low-tilt monophasic ${ }^{3,4}$ and biphasic ${ }^{5}$ waveforms are more successful than conventional higher tilt capacitorbased waveforms for the cardioversion of AF in the laboratory. The aim of this pilot study was to investigate if the low-tilt biphasic waveform was more successful and could be delivered safely in patients with persistent and induced AF. We therefore compared a low-tilt biphasic waveform with a conventional waveform for the internal cardioversion of persistent and inducible AF in patients (all other waveform parameters were identical and set according to previously published work). ${ }^{3-5}$

\section{Methods}

Patients with a history of persistent $\mathrm{AF}$ and patients with AF induced during an EPS for investigation of a supraventricular tachycardia (SVT) were invited to participate. Permission was granted from the local ethics committee. Patients with persistent $\mathrm{AF}$ had to be anticoagulated for at 
least 4 weeks prior to the procedure. Exclusion criteria were: any history of thromboembolism, intracardiac thrombus, inability to take oral anticoagulation, complete heart block, angina pectoris at rest, severe disease of native valves, or the presence of prosthetic valves or an inability to give written informed consent.

The procedure was carried out under aseptic technique in a cardiac catheterization laboratory. Patients were randomized to either the low-tilt biphasic waveform or a conventional-tilt waveform. Both waveforms were of 12-ms duration (each phase $6 \mathrm{~ms}$ ) and the second phase was $50 \%$ of the first phase (Fig. 1). These parameters had previously been studied in the laboratory and were found to be the most efficacious. ${ }^{5}$ The low-tilt waveform was delivered from a specially designed defibrillator with a $1 \mu \mathrm{F}$ capacitor, which rapidly and repeatedly discharged in order to minimize the tilt in both the positive and negative phase. Being such a small capacitor meant that each discharge and subsequent charge was so rapid that over each 6-ms phase the overall waveform tilt was close to zero. The conventional waveform was delivered from a Ventritex HVS-02 defibrillator with a single discharge from a $150 \mu \mathrm{F}$ capacitor (Ventritex, Sunnyvale, CA, USA).

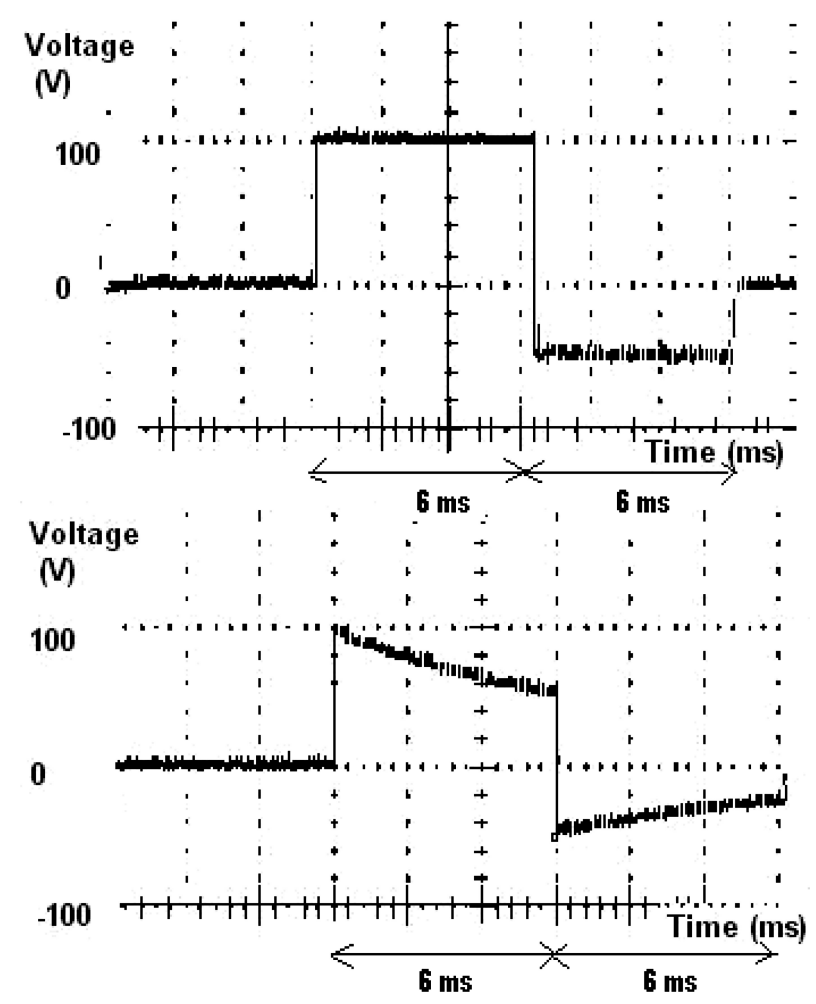

Figure 1. Voltage recording for the low-tilt biphasic waveform (top) and conventional biphasic waveform (bottom).
Shocks were synchronized to the $\mathrm{R}$ wave and were not delivered if the preceding R-R interval was $<500 \mathrm{~ms}$ (to minimize the risk of precipitating ventricular arrhythmias). ${ }^{6}$ Single-use, 6.5 Fr defibrillation catheters (Rhythm Technologies, Irvine, CA, USA) were positioned in the right atrial appendage and distal coronary sinus. Defibrillation was then carried out in a step-up voltage protocol until sinus rhythm was achieved or until a maximum phase 1 leading edge voltage of $300 \mathrm{~V}$ had been achieved. Waveform voltages were: $50 /-25 \mathrm{~V}$, $100 /-50 \mathrm{~V}, 150 /-75 \mathrm{~V}, 200 /-100 \mathrm{~V}, 240 /-120 \mathrm{~V}$, $280 /-140 \mathrm{~V}, 300 /-150 \mathrm{~V}$. Shock success was defined as the restoration of sinus rhythm for $\geq 30$ seconds after shock delivery.

For patients with persistent AF, anticoagulation was stopped 48 hours prior to the procedure and low molecular weight heparin was administered periprocedurally ( $1 \mathrm{mg} / \mathrm{kg}$ of enoxaparin). Oral anticoagulation was resumed and the heparin was discontinued when a therapeutic international normalized ratio (INR) was achieved. AF was induced by right atrial pacing $(\geq 300 / \mathrm{min})$ for those undergoing EP study. Cardioversion was only performed if the AF was sustained for a minimum period of 30 seconds.

\section{Statistics}

Cardioversion success was compared for each defibrillator using Fisher's exact test. The MannWhitney test was used for nonparametric variables. All calculations were performed with SPSS Version 11 (SPSS Inc, Chicago, IL, USA). P <0.05 was considered statistically significant. The local Ethics committee approved the study.

\section{Results}

A total of 45 patients were enrolled. Of these, 25 had persistent AF (low-tilt waveform, $n=13$; conventional waveform, $\mathrm{n}=12$ ) and 20 had $\mathrm{AF}$ induced during an EPS (low-tilt waveform, $\mathrm{n}$ $=11$; conventional waveform, $\mathrm{n}=9$ ). Baseline characteristics are summarized in Table I. There were no significant differences between the two groups. A total of 178 shocks were delivered. There was no significant arrhythmia following the delivery of any shock, or elevation of cardiac troponin I ( $>0.01 \mathrm{ng} / \mathrm{mL}$ ) following any procedure. There were no cases of thromboembolism associated with the procedure or during routine follow-up.

The low-tilt biphasic waveform significantly reduced the peak voltage required for successful cardioversion in patients with both persistent and induced AF. In patients with persistent AF the mean leading edge voltage was $223 \mathrm{~V}$ compared with $270 \mathrm{~V}$ of patients randomized to the conventional waveform $(\mathrm{P}=0.005)$. At low voltages (i.e., 
Table I.

Baseline Patient Characteristics and Parameters for Successful Shocks for the Low-Tilt and Conventional Waveform in Persistent and Inducible AF

\begin{tabular}{|c|c|c|c|c|c|}
\hline AF Type & Parameter & & Low Tilt & Conventional & $\mathbf{P}$ \\
\hline \multirow[t]{3}{*}{ Persistent AF } & Mean age \pm SD (years) & & $62 \pm 14$ & $62 \pm 12$ & Ns \\
\hline & Male (\%) & & $7(54 \%)$ & $11(92 \%)$ & 0.03 \\
\hline & Mean LA diameter $\pm \mathrm{SD}(\mathrm{mm})$ & & $44 \pm 6$ & $44 \pm 6$ & Ns \\
\hline \multirow[t]{9}{*}{$\mathrm{n}=25$} & Median AF duration (IQR, months) & & $4(2-22)$ & $4(4-6)$ & Ns \\
\hline & Previous failed external DCCs & & 3 & 1 & Ns \\
\hline & Etiology of $\mathrm{AF}$ & HTN (\%) & $7(55 \%)$ & $7(58 \%)$ & Ns \\
\hline & & VHD (\%) & $4(30 \%)$ & $3(25 \%)$ & Ns \\
\hline & & CAD (\%) & $2(15 \%)$ & $2(17 \%)$ & Ns \\
\hline & Antiarrhythmic & Class I (\%) & $1(8 \%)$ & $1(8 \%)$ & Ns \\
\hline & Drugs: & Class II (\%) & $9(70 \%)$ & $8(68 \%)$ & Ns \\
\hline & & Class III (\%) & $2(15 \%)$ & $1(8 \%)$ & Ns \\
\hline & & Class IV (\%) & $2(15 \%)$ & $2(16 \%)$ & Ns \\
\hline \multirow[t]{2}{*}{ Low tilt } & Mean voltage $\pm S D(V)$ & & $223 \pm 65$ & $270 \pm 42$ & 0.002 \\
\hline & Mean energy $\pm \mathrm{SD}(\mathrm{J})$ & & $8.2 \pm 2.6$ & $6.7 \pm 4.5$ & Ns \\
\hline \multirow{2}{*}{$\mathrm{n}=13$} & Mean impedance \pm SD (Ohms) & & $53 \pm 10$ & $56 \pm 10$ & Ns \\
\hline & Success $(\leq 300 \mathrm{~V})$ & & $10(77 \%)$ & $2(17 \%)$ & 0.005 \\
\hline \multicolumn{6}{|l|}{$\begin{array}{l}\text { Conventional } \\
n=12\end{array}$} \\
\hline \multirow[t]{2}{*}{ Induced } & Mean age \pm SD (years) & & $40 \pm 21$ & $49 \pm 13$ & Ns \\
\hline & Male (\%) & & $5(45 \%)$ & $4(44 \%)$ & Ns \\
\hline \multirow{7}{*}{$\mathrm{n}=20$} & History of AVRT (\%) & & $7(64 \%)$ & $5(56 \%)$ & Ns \\
\hline & History of AVNRT (\%) & & $3(27 \%)$ & $2(22 \%)$ & Ns \\
\hline & History of atrial flutter (\%) & & $1(9 \%)$ & $2(22 \%)$ & Ns \\
\hline & Mean voltage $\pm S D(V)$ & & $91 \pm 37$ & $158 \pm 54$ & 0.005 \\
\hline & Mean energy $\pm \mathrm{SD}(\mathrm{J})$ & & $1.6 \pm 1.2$ & $2.0 \pm .5$ & \\
\hline & Mean impedance \pm SD (Ohms) & & $49 \pm 8$ & $45 \pm 5$ & Ns \\
\hline & Success at $\leq 100 V^{*}$ & & $(82 \%)$ & $(22 \%)$ & 0.008 \\
\hline \multirow{2}{*}{\multicolumn{6}{|c|}{$\begin{array}{l}\text { Low tilt } \\
\mathrm{n}=11\end{array}$}} \\
\hline \multirow{2}{*}{\multicolumn{6}{|c|}{ Conventional }} \\
\hline & & & & & \\
\hline $\mathrm{n}=9$ & & & & & \\
\hline
\end{tabular}

*Post hoc analysis.

Abbreviations: $\mathrm{LA}=$ left atrium; HTN = hypertension;VHD = valvular heart disease; $\mathrm{CAD}=$ coronary artery disease; $\mathrm{AVRT}=\mathrm{AV}$ reentry tachycardia; AVNRT $=\mathrm{AN}$ nodal reentry tachycardia;

$\mathrm{SD}=$ standard deviation; IQR = interquartile range.

$\leq 300 \mathrm{~V}$ ) the low-tilt waveform was successful in $77 \%$ of cases compared with only $17 \%$ of cases using the conventional tilt.

In patients with induced AF the mean leading edge voltage was $91 \mathrm{~V}$ for the low-tilt waveform and $158 \mathrm{~V}$ for the conventional waveform $(\mathrm{P}=0.005)$.

There was no significant difference in the mean energy between both waveforms for either persistent (Low-tilt $8.2 \mathrm{~J}$ vs Conventional-tilt $6.7 \mathrm{~J}$ ) or induced AF (Low-tilt 1.6 J vs Conventional-tilt $2.0 \mathrm{~J})$.

\section{Discussion}

This study shows that a low-tilt waveform lowers the voltage required for the cardioversion of both persistent and induced AF. Our results compare favorably with other studies of internal cardioversion in patients with both persistent and inducible AF (see Table II). Prior to this study the lowest mean leading edge voltage reported for the internal cardioversion of persistent $\mathrm{AF}$ was $290 \mathrm{~V}$ (biphasic waveform with $65 \%$ tilt) ${ }^{7}$ and $173 \mathrm{~V}$ (biphasic with a rounded first phase) for induced AF. ${ }^{8}$ These findings, that a low-tilt 
Table II.

Summary of Results for the Internal Cardioversion of Persistent and Induced AF from Previous Studies Altering Waveform Parameters

\begin{tabular}{|c|c|c|c|c|c|c|}
\hline Author & Type of AF & $\begin{array}{l}\text { Waveform } \\
\text { Type }\end{array}$ & Tilt & $\begin{array}{c}\text { Pulse } \\
\text { Width } \\
\text { (ms) }\end{array}$ & $\begin{array}{l}\text { Catheter } \\
\text { Position }\end{array}$ & $\begin{array}{l}\text { Mean } \\
\text { Leading } \\
\text { Edge } \\
\text { Voltage } \\
\text { ( } \pm \text { Range) }\end{array}$ \\
\hline Boriani et al. ${ }^{7}$ & Persistent & Biphasic & $65 \%$ & $3.0 / 3.0$ & RA, CS & $337 \pm 104$ \\
\hline Boriani et al. ${ }^{7}$ & Persistent & Biphasic & $65 \%$ & $6.5 / 2.5$ & RA, CS & $290 \pm 76$ \\
\hline Andraghetti et al. ${ }^{12}$ & Persistent & Biphasic & $50 \%$ & $6.0 / 6.0$ & RA, CS & $320 \pm 45$ \\
\hline Gasparini et al. ${ }^{13}$ & Persistent & Biphasic & $65 \%$ & $6.0 / 6.0$ & RA, CS / LPA & $320 \pm 60$ \\
\hline Tse et al. ${ }^{14}$ & Persistent & Biphasic & $60 \%$ & $3.0 / 3.0$ & RA, CS & $343 \pm 8$ \\
\hline Lévy et al. ${ }^{15}$ & Persistent & Biphasic & $60 \%$ & $3.0 / 3.0$ & RA, CS & $311 \pm 60$ \\
\hline Schmitt et al. ${ }^{16}$ & Persistent & Biphasic & $65 \%$ & $3.0 / 2.0$ & RA, CS / PA & - \\
\hline Boriani et al. ${ }^{7}$ & Persistent & Biphasic & $60 \%$ & $3.0 / 3.0$ & RA, CS / LPA & $345 \pm 64$ \\
\hline Ammer et al. ${ }^{17}$ & Persistent & Biphasic & $65 \%$ & $3.0 / 3.0$ & $\mathrm{RA}, \mathrm{CS}$ & 355 \\
\hline Ammer et al. ${ }^{17}$ & Persistent & Biphasic & $65 \%$ & $6.0 / 6.0$ & RA, CS & 254 \\
\hline Socas et al. ${ }^{18}$ & Persistent & Biphasic & $60 \%$ & $3.0 / 2.0$ & RA, CS / PA & $300 \pm 68$ \\
\hline Mairesse et al. ${ }^{19}$ & Persistent & Monophasic & - & - & RA, CS & - \\
\hline Mairesse et al. ${ }^{19}$ & Persistent & Biphasic & - & - & RA, CS & - \\
\hline Murgatroyd et al. ${ }^{20}$ & Induced & Biphasic & $65 \%$ & $3.0 / 3.0$ & RA, CS & $230 \pm 55$ \\
\hline Harbinson et al. ${ }^{21}$ & Induced & Biphasic & $\begin{array}{l}\text { Rounded } \\
\text { 1st phase }\end{array}$ & $3.0 / 3.0$ & RA, CS & 173 \\
\hline Cooper et al. ${ }^{22}$ & Induced & Biphasic & $60 \%$ & $7.5 / 2.5$ & RA, CS & $166 \pm 67$ \\
\hline Cooper et al. ${ }^{22}$ & Induced & Biphasic & $60 \%$ & $5.0 / 5.0$ & RA, CS & $241 \pm 35$ \\
\hline Cooper et al. ${ }^{22}$ & Induced & Monophasic & $60 \%$ & $10 \mathrm{~ms}$ & RA, CS & $320 \pm 84$ \\
\hline Socas et al. ${ }^{18}$ & Induced & Biphasic & $65 \%$ & $3.0 / 2.0$ & RA, CS /PA & $270 \pm 67$ \\
\hline Tse et al. ${ }^{14}$ & Induced & Biphasic & $60 \%$ & $3.0 / 3.0$ & RA, CS & $192 \pm 15$ \\
\hline Jung et al. ${ }^{23}$ & Induced & Biphasic & $40 \%$ & $2.0 / 2.0$ & RA,CS & $97 \pm 35$ \\
\hline Jung et al. ${ }^{23}$ & Induced & Biphasic & $80 \%$ & $2.0 / 2.0$ & RA,CS & $252 \pm 64$ \\
\hline
\end{tabular}

Abbreviations: $\mathrm{RA}=$ right atrial; $\mathrm{CS}=$ coronary sinus; $\mathrm{PA}=$ pulmonary artery.

waveform lowers the peak voltage for successful cardioversion, support previous laboratory studies. $^{3-5}$ It has been shown in several studies that peak voltage is directly related to shock tolerability rather than the total delivered energy for internal cardioversion. ${ }^{9,10}$ Although there is always a level of discomfort associated with all shocks it can be postulated that lowering the mean voltage and increasing the overall success at low voltages is beneficial in improving tolerability to the extent that this may reduce the sedation requirements for internal cardioversion. This parameter was not directly looked at in this study. It must also be noted that there was no significant difference in the total energy required for the successful cardioversion of both persistent and induced AF. Lower tilt waveforms are generally associated with a higher total energy. Interestingly, this was not significantly higher (and in fact was slightly lower in the induced cases) with our low-tilt waveform.

There are several theoretical explanations why lowering the waveform tilt may increase shock success. The lower success of conventional capacitor-based waveforms can be correlated with the fundamental law of electrostimulation. ${ }^{11}$ Failure of defibrillation may be due to lack of depolarization in the periphery of the defibrillation field (farfield). The area of myocardium that is furthest from the electrodes may not be exposed to a high enough defibrillating voltage throughout the duration of the shock. In contrast, low-tilt waveforms maintain a steady potential difference throughout the shock duration.

This study is limited by small patient numbers but provides useful information that may prompt further work in the cardioversion of $\mathrm{AF}$ as well 
as in standard external cardiac defibrillators and ventricular defibrillation. The technology required to produce this low-tilt waveform is simple and could easily be incorporated into an implantable device.

\section{Conclusions}

This novel low-tilt biphasic waveform was highly successful for the cardioversion of both

\section{References}

1. Kusumoto FM. Internal atrial and ventricular defibrillation during electrophysiology procedures. J Interv Card Electrophysiol 2005; 13(Suppl):71-78

2. Oral H, Pappone C, Chugh A, Good E, Bogun F, Pelosi F Jr., Bates ER, et al. Circumferential pulmonary-vein ablation for chronic atrial fibrillation. N Engl J Med 2006; 354:934-941.

3. Manoharan G, Evans N, Kidwai B, Allen D, Anderson J, Adgey J. Novel passive implantable atrial defibrillator using transcutaneous radiofrequency energy transmission successfully cardioverts atrial fibrillation. Circulation 2003; 108:1382-1388.

4. Manoharan G, Evans N, Allen D, Anderson J, Adgey J. Comparing the efficacy and safety of a novel monophasic waveform delivered by the passive implantable atrial defibrillator with biphasic waveforms in cardioversion of atrial fibrillation. Circulation 2004; 109 1686-1692.

5. Walsh SJ, Manoharan GM, Escalona OJ, Santos J, Evans N, Anderson J McC, Stevenson M, et al. Novel rectangular biphasic and monophasic waveforms delivered by a radiofrequency powered defibrillator compared with conventional capacitor based waveforms in transvenous cardioversion of atrial fibrillation. Europace 2006; 8:873-880.

6. Ayers GM, Alferness CA, Ilina M, Wagner DO, Sirokman WA, Adams JM, Griffin JC. Ventricular proarrhythmic effects of ventricular cycle length and shock strength in a sheep model of transvenous atrial defibrillation. Circulation 1994; 89:413-422.

7. Boriani G, Biffi M, Bronzetti G, Ayers GM, Zannoli R, Branzi A, Capucci A, et al. Efficacy and tolerability in fully conscious patients of transvenous low energy internal atrial cardioversion of atrial fibrillation. Am J Cardiol 1998; 81:241-244.

8. Harbinson MT, Allen JD, Imam Z, Dempsey G, Anderson JM, Ayers GM, Adgey AA. Rounded biphasic waveform reduces energy requirements for transvenous catheter cardioversion of atrial fibrillation and flutter. Pacing Clin Electrophysiol 1997; 20:226-229.

9. Tomassoni G, Newby KH, Kearney MM, Brandon MJ, Barold H, Natale A. Testing different biphasic waveforms and capacitances: Effect on atrial defibrillation threshold and pain perception. J Am Coll Cardiol 1996; 28:695-699.

10. Boriani G, Biffi M, Silvestri P, Martignani C, Valzania C, Diemberger I, Moulder C, et al. Mechanisms of pain associated with internal defibrillation shocks: Results of a randomized study of shock waveform. Heart Rhythm 2005; 2:708-713.

11. Irnich W. The fundamental law of electrostimulation and its application to defibrillation. Pacing Clin Electrophysiol 1990; 13:14331447 persistent and inducible $\mathrm{AF}$ at a very low leading edge voltage extending our previous findings into the clinical arena. This waveform could be used for the cardioversion of AF during electrophysiology studies as well as in patients who have had failed transthoracic cardioversions. It should also prompt further work into optimizing waveform tilt for the defibrillation of ventricular arrhythmias.

12. Andraghetti A, Scalese M. Safety and efficacy of low-energy cardioversion of 500 patients using two different techniques. Europace 2001; 3:4-9.

13. Gasparini G, Bonso A, Themistoclakis S, Giada F, Raviele A. Lowenergy internal cardioversion in patients with long-lasting atrial fibrillation refractory to external electrical cardioversion: Results and long-term follow-up. Europace 2001; 3:90-95.

14. Tse HF, Lau CP, Ayers GM. Dose-response relationship for successful internal atrial defibrillation. Pacing Clin Electrophysiol 2003; 26:1249-1253.

15. Lévy S, Ricard P, Lau CP, Lok NS, Camm AJ, Murgatroyd FD, Jordaens LJ, et al. Multicenter low energy transvenous atrial defibrillation (XAD) trial results in different subsets of atrial fibrillation. J Am Coll Cardiol 1997; 29:750-755.

16. Schmitt C, Alt E, Plewan A, Ammer R, Leibig M, Karch M, Schömig A. Low energy intracardiac cardioversion after failed conventional external cardioversion of atrial fibrillation. J Am Coll Cardiol 1996; 28:994-999.

17. Ammer R, Alt E, Ayers G, Schmitt C, Pasquantonio J, Schmidt M, Putter K, et al. Pain threshold for low energy intracardiac cardioversion of atrial fibrillation with low or no sedation. Pacing Clin Electrophysiol 1997; 20:230-236.

18. Socas AG, Ricard P, Taramasco V, Guenoun M, Lévy S. Transvenous cardioversion of atrial fibrillation using low-energy shocks. J Inter Card Electrophysiol 1997; 1:125-129.

19. Mairesse GH, Raepers M, Legrand I, Baroud I, Deheneffe Y, Emonts M, Paquay JL, et al. Internal cardioversion of persistent atrial fibrillation using rectilinear biphasic waveform. J Interv Card Electrophysiol 2003; 9:371-375.

20. Murgatroyd FD, Slade AK, Sopher SM, Rowland E, Ward DE, Camm AJ. Efficacy and tolerability of transvenous low energy cardioversion of paroxysmal atrial fibrillation in humans. J Am Coll Cardiol. 1995; 25:1347-1353.

21. Harbinson MT, Allen JD, Imam Z, Dempsey G, Anderson JM, Ayers GM, Adgey AA. Transvenous catheter cardioversion of atrial tachycardias with a rounded biphasic waveform reduces voltage, energy and discomfort. Irish J Med Sci. 166(Suppl7);14.

22. Cooper RA, Johnson EE, Wharton JM. Internal atrial defibrillation in humans improved efficacy of biphasic waveforms and the importance of phase duration. Circulation 1997; 95:1487-1496.

23. Jung J, Hahn SJ, Heisel A, Buob A, Schubert BD, Siaplaouras S. Defibrillation efficacy and pain perception of two biphasic waveforms for internal cardioversion of atrial fibrillation. J Cardiovasc Electrophysiol 2003; 14:837-840. 